\title{
Food safety, sanitation and hygiene practices among street food vendors in Pokhara, Kaski
}

\author{
Nisha Bhandari ${ }^{1}$, Babu Ram Bhusal2* \\ 'Pokhara Nursing Campus, Institute of Medicine, Tribhuvan University, \\ 2Ministry of Health and Population, National Health Training Centre
}

\begin{abstract}
Introduction: Street foods are unique and convenient urban food supply, but meanwhile it lacks food hygiene and safety posing a major public health risk. Thus, the study aimed to identify the food safety, sanitation and hygiene practices of street food vendors. Methods: The study was cross-sectional including seventy vending sites which were selected conveniently and conducted in May-June, 2019. A structured interview schedule and observation checklist was used as a data collection tool. Results: The mean age of the respondents was $38.06( \pm 10.417)$ years with more than half $(61.4 \%)$ being females. The majority (77.1\%) had formal education, $37.1 \%$ earned more than 40,000 per month and $86 \%$ had not taken any food hygiene training. Eighty percent of the respondents had fixed stalls with $82.9 \%$ selling freshly cooked food and $75 \%$ preparing it in the marketplace. About $84 \%$ of the respondents revealed diarrhea as the most prevalent disease caused by poor food hygiene. Very few (27\%) had their health check-up regularly and $68.6 \%$ prepared food when they were ill. Almost half of the respondents heated food before serving, $58 \%$ washed dishes with tap water, $98.6 \%$ washed raw food before preparation and all of them washed cooking dishes daily. About half (48.6\%) of the respondents re-used oil while cooking and $77.1 \%$ had a refrigeration facility. The practice of food vending was found to be good $(>50)$ in $54.3 \%$ and sanitation was good ( $>50 \%$ ) in $60 \%$. Conclusions: Although the overall sanitary conditions of the vending sites were good, still there is need for improvement in most of the aspects of the sanitary condition.
\end{abstract}

Keywords: Food hygiene, food hygiene practices, food sanitation, food vendors, Nepal, street foods.

\section{*Correspondence:}

Babu Ram Bhusal,

Senior Public Health Officer,

Ministry of Health and Population, National Health Training Centre.

Email: bhusalbaburam313@gmail.com

Submitted: April 4, 2021

Accepted: November 16, 2021

To cite: Bhandari N, Bhusal BR. Food safety, sanitation and hygiene practices among street food vendors in Pokhara, Kaski. JGMC Nepal. 2021;14(2):127-32.

DOI: $10.3126 /$ jgmcn.v14i2.36297

\section{INTRODUCTION}

The trend of street food vending is increasing worldwide due to fast urbanization and alarmingly increasing hasty lifestyles. ${ }^{1}$ The street foods have unique flavours, and also offers business opportunities for developing entrepreneurs. ${ }^{2}$ Despite its benefit, food safety is a major concern as these foods are generally prepared and sold under unhygienic conditions ${ }^{3}$ and food-borne illnesses contribute to millions of illnesses and thousands of deaths annually. ${ }^{4}$

The majority of the food vendors had no previous training in food safety $^{5}$ and most of them do their business haphazardly with poor knowledge and practice., ${ }^{5}$ They do not give due to preference to cover their food items, no spoon was used to serve the food and without the use of head covering and apron. ${ }^{7}$ In the context of Nepal, the market for street foods is booming and limited studies have been carried out regarding food safety and hygiene through its great impact on the health of the public. And hence, the researcher aimed to identify food safety and hygiene practices among street vendors in Pokhara to generate evidence for concerned authorities to establish appropriate public health intervention and legal regulation. 


\section{METHODS}

A descriptive cross-sectional study design was conducted among seventy registered vending units of Pokhara Metropolitan City, Gandaki Province, Nepal which were selected conveniently. Seven wards were selected purposively and ten vending units from each ward were taken conveniently. Only the few numbers of vending sites were systematically documented and registered, and this study excluded non-registered vending sites and hence the sample was limited to 70 , ten registered vending sites from each ward. The information was collected from the food vendor who was directly involved in preparing the food from each vending unit. The period of data collection extended from May 2019 to June 2019.

The structured interview schedule was used to collect the data on the background characteristics of the respondent and general information regarding vending sites. An observational checklist was used for further exploration of food sanitation and hygiene practices which was modified from the "WHO essential requirement for the safety of street-vended foods". The area was observed while vending unit served for one customer that took about a half-hour to 2 hours. Data entry and analysis was carried out simultaneously with data collection. Pre-testing of the instrument was done in $10 \%$ of the sample and necessary modification was made accordingly.

Data entry and analysis was done using SPSS version 20.0 and descriptive analysis was done. Altogether 15 items were assessed for the vending practices. A total of "1" marks was given for correct practice and " 0 " for wrong practice. The total score was obtained by summing up the marks gained from each item which was then converted to $100 \%$. The practice scoring $\leq 50 \%$ was considered as poor practice and a score $>50 \%$ was marked as good practice. For sanitary conditions, eight parameters were assessed. A total of a " 1 " mark was given for correct sanitation and a " 0 " mark was given for the absence of correct sanitation. The total score was taken as $100 \%$ which was then categorized as $\leq 50 \%$ having poor sanitation and $>50 \%$ for having good sanitation taking reference of the study by Okojie and Isha ${ }^{8}$

The ethical approval was taken from the Ethical Review Board of Nepal Health Research Council (Ref. no 3052). The permission to conduct the study was obtained from Pokhara Metropolitan City.

\section{RESULTS}

1. Background characteristics of the respondents
Of all the respondents, the mean age was found to be 38.06 $( \pm 10.417)$ years with more than half being females $(61.4$ $\%)$. The majority (77.1\%) had formal education. Most of them $(90 \%)$ were doing vending as a full-time job. Thirtyseven per cent had been engaged in food vending for more than five years. More than three quarters (85.7\%) had not taken any training regarding food hygiene and sanitation (Table 1).

Table 1: Background characteristics of the respondents $(\mathrm{N}=70)$

\begin{tabular}{|c|c|c|}
\hline Variables & Number & Percentage \\
\hline \multicolumn{3}{|l|}{ Age (in years) } \\
\hline$\leq 40$ & 34 & 48.5 \\
\hline$>40$ & 36 & 51.42 \\
\hline \multicolumn{3}{|c|}{ Mean $( \pm S D)=38.06( \pm 10.417) ;$ Min: 16 ; Max: 60} \\
\hline \multicolumn{3}{|l|}{ Sex } \\
\hline Male & 27 & 38.6 \\
\hline Female & 43 & 61.4 \\
\hline \multicolumn{3}{|l|}{ Education } \\
\hline Formal & 54 & 77.1 \\
\hline Informal & 16 & 22.9 \\
\hline \multicolumn{3}{|l|}{ Occupation type } \\
\hline Full time & 63 & 90.0 \\
\hline Part-time & 7 & 10.0 \\
\hline \multicolumn{3}{|c|}{ Number of years in business } \\
\hline$<1$ year & 12 & 17.1 \\
\hline 1 to 3 & 22 & 31.4 \\
\hline 3 to 5 & 10 & 14.3 \\
\hline$>5$ & 26 & 37.1 \\
\hline Food safety training & 10 & 14.3 \\
\hline \multicolumn{3}{|l|}{ If yes, training by } \\
\hline Cook training by hotels & 10 & 14.3 \\
\hline \multicolumn{3}{|l|}{ Type of stall } \\
\hline Fixed stall & 56 & 80.0 \\
\hline Improved food stall & 14 & 20.0 \\
\hline
\end{tabular}

\section{Food safety and hygiene of the vending unit}

Table 2 portrays that around four fifth of the respondents had fixed stalls (80\%) and was selling freshly cooked food (83\%). Three fourth of the vendors prepared it in the market place and $38 \%$ prepared them in the morning.

Table 2: Type of food and preparation of food in the vending unit $(\mathrm{n}=70)$

\begin{tabular}{lcc}
\hline Variables & Number & Percentage \\
Type of food* & & \\
Freshly cooked & 58 & 82.9 \\
Pre-prepared & 42 & 60.0 \\
Raw Foods & 17 & 24.3 \\
Place of preparation & & \\
$\quad$ At home & 12 & 17.1 \\
At market place & 53 & 75.7 \\
Home+ market place & 5 & 7.1 \\
\end{tabular}




\begin{tabular}{lcc} 
Time of preparation & & \\
Morning & 27 & 38.6 \\
During the sale & 23 & 32.9 \\
Morning +During the sale & 17 & 24.3 \\
One night before and morning & 3 & 4.3 \\
\hline *multiple responses &
\end{tabular}

About $84 \%$ of the respondent revealed diarrhea as the most prevalent disease caused by poor food hygiene. Almost 50\% heated food before serving, 58.5\% washed dishes with tap water. More than half (62.9\%) washed their hand with water only, about half $(48.6 \%)$ of the respondents re-used oil while cooking. Approximately $77 \%$ had clean and fresh raw foods. In $34.3 \%$ of vending unit cross-contamination was present and in about $77 \%$ refrigeration facility was available as shown in table 3 .

Table 3. Food safety and hygiene of the vending unit $(n=70)$

\begin{tabular}{lcc}
\hline Variables & Number & Percentage \\
Symptoms/Disease caused by poor hygiene* & 68 & \\
$\quad$ Diarrhoea and vomiting & 13 & 18.6 \\
$\quad$ Abdominal pain & 37 & 52.9 \\
$\quad$ Other & 35 & \\
Heat food before serving & 7 & 50.0 \\
$\quad$ Yes & 28 & 10.0 \\
$\quad$ No & & 40.0 \\
$\quad$ Heating not required & 6 & 8.6 \\
Wash dishes & 41 & 58.5 \\
$\quad$ Washing with bucket water & 23 & 32.8 \\
$\quad$ Tap water & & \\
Drum water & 44 & 62.9 \\
Hand washing & 26 & 37.1 \\
$\quad$ Only with water & & \\
$\quad$ With soap and water & 19 & 48.6 \\
Re-use of oil & 54 & 24.3 \\
$\quad$ Yes & 34 & 27.1 \\
No & 17 & 77.1 \\
Not applicable & & \\
Refrigeration facility & & \\
*multiple responses & & \\
\end{tabular}

\section{Observed vending and food handling practices and sanitary condition of the vending sites}

Approximately $66 \%$ covered their food, $70 \%$ vending sites were exposed to flies, and $72.9 \%$ grilled semi-prepared food. Almost 79\% wore jewellery which preparing food, $45.7 \%$ had long nails, $10 \%$ had cut on their skin, only $5.7 \%$ and $10 \%$ wore a head covering and apron respectively. The majority (65.7\%) wore clean clothes, $14.3 \%$ blew air in cellophane/ plastic bags, $74.3 \%$ served food with bare hands whereas $20 \%$ used spoons and only $1.4 \%$ use gloves. Almost half (51.4\%) concurrently served food and received money and $12.9 \%$ picked nose while preparing food. (Table 4)
Table 4. Observed vending and food handling practices of the vending sites $(\mathrm{n}=70)$

\begin{tabular}{lcc}
\hline Variables & Number & Percentage \\
Vending practices & 46 & 65.7 \\
Food sold from tray/ basin with covering & 49 & 70.0 \\
Food exposed to flies & 51 & 72.9 \\
Semi prepared food fried/grilled/baked before the sale & 55 & 78.6 \\
Vendor wearing hand jewellery & 32 & 45.7 \\
A vendor having long nails & 7 & 10.0 \\
A vendor having boil/cut in the hands & 4 & 5.7 \\
Vendor wearing headgear & 1 & 1.4 \\
Vendor wearing gloves & 52 & 74.3 \\
Serving food with bare hand & 17 & 20.0 \\
Serving food with serving fork or spoon or gloves & 7 & 10.0 \\
Vendor wearing apron & 46 & 65.7 \\
Vendor wearing clean attire & 10 & 14.3 \\
Blowing air into cellophane/plastic bag before serving. & 36 & 51.4 \\
Concurrent serving of food and collection of money & 9 & 12.9 \\
Scratching hair, picking nose while serving food & & \\
Level of food hygiene practice & 38 & 54.2 \\
Good ( $>50 \%$ ) & 32 & 45.7 \\
Poor ( $\leq 50 \%$ ) & &
\end{tabular}

Most of the vending units (91.4\%) had dustbin however only $24.3 \%$ had waste disposing sites nearby. About $65.7 \%$ had the facility of tap water to clean dishes, $24.3 \%$ had the facility of the towel and $61.4 \%$ had soap to wash hands. Sixty percent had cockroaches/rats present in the vending site and $11.4 \%$ with water collectors do not clean the collector after each use (Table 5).

Table 5. The observed sanitary condition of vending sites $(n=70)$

\begin{tabular}{lcc}
\hline Variables & Number & Percentage \\
Sanitary condition of vending sites/ premises & & \\
Presence of waste bin & 64 & 91.4 \\
Presence of nearby refuse dump site & 17 & 24.3 \\
Presence of clean hand towel & 17 & 24.3 \\
Presence of soap for hand-washing & 43 & 61.4 \\
Presence of rats/ cockroaches & 42 & 60.0 \\
Washing utensil with soap and running water & 46 & 65.7 \\
Clean water collector or water disposal & 47 & 67.1 \\
Presence of non-porous surface & 38 & 54.3 \\
Level of environmental sanitation & & \\
Good (>50\%) & 42 & 60.0 \\
Poor ( $\leq 50 \%)$ & 28 & 40.0 \\
\hline
\end{tabular}

\section{DISCUSSION}

In this study, about $83 \%$ of street food vendors sell freshly cooked food and most of them (75\%) prepare it in the marketplace. About 38\% of foods are prepared in the morning. Likewise, the study conducted by Oluwasen and Musa et $\mathrm{al}^{9}$ revealed 33\% of vendors prepare food in advance. Also, the study done in India found that $62.5 \%$ prepare their food in the market place and less than half prepare food in the morning and during the sale. ${ }^{8}$ The 
present study documented that majority (92.9\%) have heard of cleanliness and nearly half (48.6\%) knew about cleanliness by themselves. About $84 \%$ of the respondent revealed diarrhoea as the most prevalent disease caused by poor hygiene. Likely, Isara et $\mathrm{al}^{10}$ found $75.2 \%$ mentioned diarrhoea as the most common symptom. Similarly, the study done by Iwu et $\mathrm{al}^{11}$ found $87 \%$ were aware of food hygiene being television as the main source of information and $55.5 \%$ knew diarrhoeal disease to be most commonly caused by poor hygiene. Very few (27\%) have their health check-up regularly whereas it is higher in the other study which showed $68.5 \% .{ }^{11}$ About $69 \%$ prepare food when they are ill. Almost 50\% heat food before whereas other study found only $23.1 \%$ re-heating of food. ${ }^{8}$ Almost all (98.6\%) wash raw food before preparation which is similar to the study done by Isara et $\mathrm{al}^{10}$ which showed $100 \%$ washing of food before preparation. It was found that more than half of the respondents (55.7\%) wash their hands with water only which is far lower than other studies which mentioned 95.5\%. ${ }^{10}$ About half (48.6\%) of the respondents re-use oil while cooking. Approximately $77 \%$ have clean and fresh raw foods. In $34.3 \%$ of vending units cross-contamination was present and in about $77 \%$ refrigeration facility was available.

The present study found that $65.7 \%$ covered their food which is in contrast with other studies which showed approximately $95 \%$ covering of food ${ }^{8,10}$ whereas other studies revealed $39 \%$ to $55 \%$ covering of food.,13,14 In this study almost $79 \%$ wear jewellery while preparing food while in contrast Hill et al ${ }^{14}$ found $21.6 \%$ use of jewellery and only $8.8 \%$ use of jewellery was identified in the study of Okojie et al. ${ }^{8}$ The present study showed $45.7 \%$ of respondents have long nails, $10 \%$ have cut on their skin, $5.7 \%$ and $10 \%$ wear head covering and apron respectively. Regarding unmanaged nails findings, other studies showed almost similar findings ranging from $15 \%$ to $53 \% 11,13,14$ and $18.9 \%$ have undressed skin lesion ${ }^{9}$ and $27.3 \%$ have cut on their hand. ${ }^{8}$ The apron use ranges from $23 \%$ to $85 \%$ in different studies ${ }^{8,9,11,12}$ whereas hair covering was in between $15 \%$ to $99 \% .^{7,9,12,13}$ Seventy vending sites were exposed to flies in this study while the study of Musa et $\mathrm{al}^{9}$ found $44.3 \%$ exposure to flies and Okojie et $\mathrm{al}^{8}$ revealed it as $27.7 \%$.

The majority (65.7\%) wear clean clothes which are almost similar to the study done by Iwu et al. ${ }^{11}$ comprising $74 \%$. Approximately, $14.3 \%$ blew air in cellophane/ plastic bags, $74.3 \%$ serve food with bare hands whereas $20 \%$ used a spoon and only $1.4 \%$ used gloves. Almost half (51.4\%) concurrently serve food and receive money. Isara et $\mathrm{al}^{10}$ found $23.2 \%$ blew air in plastic which is almost close to this study and $82 \%$ handle money and food at the same time which is higher compared to this study. Also, the study by Hill et al. ${ }^{13}$ identified $76.6 \%$ of vendors handle money and food at the same time. The findings are higher for Singh and other ${ }^{7}$ which showed 98\% serve food with a bare hand, $74 \%$ did not use spoon or fork to serve food and $98 \%$ do not use gloves which is similar to this study. Surprisingly, the study done by Monney et al. ${ }^{12}$ found $100 \%$ use of a spoon to serve food. It was observed that $12.9 \%$ picked nose or scratch hair while serving food which is higher $(2.8 \%)$ than the study done by Isara et al. ${ }^{10}$ These all are the critical source of contamination of food in different ways.

Most of the vending units (91.4\%) have dustbins however only $24.3 \%$ have a waste disposing site nearby. In contrast, the study by Okojie et al. $^{8}$ found $43.4 \%$ of the vending unit without dustbin and only $14.3 \%$ had a refuse site. Meanwhile, Dajaan revealed $91 \%$ of the vending site had no dustbin present. ${ }^{14}$ This study showed about $66 \%$ have the facility of tap water to clean dishes. In contrast, the study done by Dajaan et $\mathrm{al}^{14}$ found $91 \%$ had no running water present to wash dishes while Okojie and Isah ${ }^{8}$ found $71.4 \%$ with washbasin. Around $24 \%$ have the facility of the towel and $61.4 \%$ have soap to wash hands in this study. The study by Iwu et $\mathrm{al}^{11}$ found $60 \%$ have clean towels, soap and water facilities. Likely, Okojie et $\mathrm{al}^{8}$ found $73.4 \%$ with hand towels present and $76.9 \%$ had soap available to wash hands. Sixty per cent have cockroaches/rats present in the vending site and $11.4 \%$ with water collectors do not clean the collector after each use and $54.3 \%$ have nonporous surfaces on the table. The study by Iwu et $\mathrm{al}^{11}$ found $85 \%$ have disease vectors in the site and $66 \%$ have poor service tables and surroundings. In contrast, another study identified only $2.4 \%$ had rats/cockroaches. ${ }^{8}$

The study design is cross-sectional has its inherent set of limitations. Sanitation and hygiene levels were recorded based on an observation checklist. The same level of hygiene doesn't need to be maintained at all times as when the interviewer visited the food vendor. There was no component of follow-up in the study. In this study, we looked at only a few numbers of hygiene and sanitation practices. Those vendors who were not registered did not have a chance to participate in the study.

\section{CONCLUSIONS}

Overall, the sanitary conditions of the vending sites were 
good. But the major areas which put major hazards to health are poor hand washing practice, no regular health checkup, re-use of oil, poor use of personal protective equipment and presence of flies and other vectors like cockroaches and rats in the vending sites which needs due attention.

This study recommends that every vendor, helper, or food handler should undergo basic training in food hygiene and sanitation; establishment of a code of practices for street food business. There should be provision of basic water and waste management facilities, and constant supervision by the respective authority.

In major cities of Nepal, there are large numbers of local eateries and there is no systematic documentation of the number of street food vendors and their hygiene practices. Thus, this study can be used to generate the evidence to establish appropriate public health intervention and legal regulation for street food vending practices.

ACKNOWLEDGEMENT: Prof. Dr. Vikash KC, Asso. Prof. Dr. Damaru Prasad Paneru and Asso. Prof. Dr. Nuwadutta Subedi for their constructive suggestions and meticulous attention. Ministry of Social Development for providing the opportunity to carry out this study with financial aid.

CONFLICT OF INTEREST: None declared

SOURCE OF FUNDING: Disease Control and Research Section, Ministry of Social Development, Gandaki Province, Pokhara, Nepal

\section{REFERENCES}

1. Samapundo S, Climat R, Xhaferi R, Devlieghere F. Food safety knowledge, attitudes and practices of street food vendors and consumers in Port-au-Prince, Haiti. Food control. 2015 Apr 1;50:457-66. DOI: 10.1016/j. foodcont.2014.09.010.

2. WHO. Essential safety requirements for streetvended foods. Food Safety Unit Division of Food and Nutrition, World Health Organization. 1996. Retrieved from https://apps.who.int/iris/ bitstream/handle/10665/63265/WHO_FNU_ FOS_96.7.pdf?sequence $=1 \&$ isAllowed $=y$ on 2019 , April 2.

3. Donkor ES, Kayang BB, Quaye J, Akyeh ML. Application of the WHO keys of safer food to improve food handling practices of food vendors in a poor resource community in Ghana. International journal of environmental research and public health. 2009 Nov;6(11):2833-42. DOI: $10.3390 /$ ijerph6112833.

4. PillingVK, Brannon LA, Shanklin CW, Roberts KR, Barrett $\mathrm{BB}$, Howells AD. Food safety training requirements and food handlers' knowledge and behaviors. Food protection trends. 2008;28(3):192-200. Retrieved from http://hdl.handle.net/2097/805 on ???????.

5. Baş M, Ersun AŞ, Kıvanç G. The evaluation of food hygiene knowledge, attitudes, and practices of food handlers' in food businesses in Turkey. Food control. $2006 \mathrm{Apr}$ 1;17(4):317-22. DOI: 10.1016/j.foodcont.2004.11.006

6. Faruque $\mathrm{Q}$ Haque QF, Shekhar HU, Begum S. Institutionalization of healthy street food system in Bangladesh: A pilot study with three wards of Dhaka City Corporation as a model. National Food Policy Capacity Strengthening Programme (NFPCSP). 2010 Feb. Retrieved from http://fpmu.gov.bd/agridrupal/ sites/default/files/pR_7_of_04_Final_Techncial_ Report_-_Approved.pdf, on March 21, 2019.

7. Singh AK, Singh NP, Chaturvedani AK. Food safety and hygiene practices among street food vendors in Noida, Uttar Pradesh, India. International Journal of Current Microbiology and Applied Sciences. 2018;7(9):2340-7. DOI: 10.20546/ijcmas.2018.709.291.

8. Okojie PW, Isah EC. Sanitary conditions of food vending sites and food handling practices of street food vendors in Benin City, Nigeria: implication for food hygiene and safety. Journal of environmental and public health. 2014 Mar;2014. DOI: 10.1155/2014/701316.

9. Musa OI, Akande TM. Food hygiene practices of food vendors in secondary schools in Ilorin. Niger Postgrad Med J. 2003 Sep 1;10(3):192-6. Retrieved from https:// www.researchgate.net/publication/8945316 on March 24, 2019.

10. Isara AR, Osagie JO, Omodamwen N, Omorodion IS. Food hygiene and safety practices of mobile food vendors in Benin City, Nigeria. Sudan Medical Monitor. 2017 Apr 1;12(2):51. DOI: 10.4103/summ.summ_36_17.

11. Iwu AC, Uwakwe KA, Duru CB, Diwe KC, Chineke HN, Merenu IA, Oluoha UR, Madubueze UC, Ndukwu E, Ohale I. Knowledge, attitude and practices of food hygiene among food vendors in Owerri, Imo State, Nigeria. Occupational Diseases and Environmental Medicine. 
2017;5(01):11-25. DOI: 10.4236/odem.2017.51002

12. Monney I, Agyei D, Owusu W. Hygienic practices among food vendors in educational institutions in Ghana: the case of Konongo. Foods. 2013 Sep;2(3):282-94. DOI: 10.3390 /foods2030282.

13. Hill J, Mchiza Z, Puoane T, Steyn NP. Food sold by street-food vendors in Cape Town and surrounding areas: a focus on food and nutrition knowledge as well as practices related to food preparation of streetfood vendors. Journal of Hunger \& Environmental Nutrition. 2019 May 4;14(3):401-15. DOI: 10.1080/19320248.2018.1434104.

14. Dajaan DS, Addo HO, Luke O, Eugenia A, Amshawu A, Kwasi NA. Food hygiene awareness and environmental practices among food vendors in basic schools at Kintampo township, Ghana. Food and Public Health. 2018;8(1):13-20.DOI: 10.5923/j.fph.20180801.03. 